\title{
Análise dos fatores que influenciam a qualidade de vida dos portadores de deficiência nas regiões do Triângulo Mineiro e Alto Paranaíba de Minas Gerais
}

\section{Analysis of the factors that influence the quality of life of people with disabilities in the Triângulo Mineiro and Alto Paranaíba regions of Minas Gerais}

DOI: $10.46814 / \operatorname{lajdv} 3 n 4-045$

Recebimento dos originais: 01/05/2021

Aceitação para publicação: 31/06/2021

\section{Bruna Queiroz De Melo Prado}

Especialista em Estatística pela Universidade de Brasília (Unb)-Brasília(DF), Brasil. Endereço para correspondência: Rua Joaquim Silva Carvalho, 37, Segismundo Pereira, Uberlândia - MG.

E-mail: bruna.est.ufu@gmail.com.

\section{Nádia Giaretta Biase}

Doutora em Estatística e Experimentação Agropecuária pela Universidade Federal de Lavras (UFLA) - Lavras (MG), Brasil. Professora Associada da Faculdade de Matemática da UFU - Uberlândia (MG), Brasil. Endereço para correspondência: Nádia Giaretta Biase - Faculdade de Matemática, Universidade Federal de Uberlândia - Avenida João Naves de Ávila, 2.121 - Campus Santa Mônica - Bloco 1F120 - 38408-100 - Uberlândia (MG), Brasil

E-mail: nadiabiase@ufu.br

\section{RESUMO}

Ao longo da história sempre existiram pessoas com alguma limitação física, sensorial ou intelectual, cuja trajetória foi marcada pela ignorância, indiferença, preconceito e lutas em busca da inclusão social. No Brasil, o censo de 2000 registrou 24,5 milhões de pessoas com algum tipo de deficiência. A avaliação dos deficientes de uma região permite conhecer melhor as condições e realidades nas quais essas pessoas estão inseridas. São poucos os estudos voltados às pessoas com deficiência, especificamente em relação à qualidade de vida dessas pessoas nas regiões do Triângulo Mineiro e Alto Paranaíba de Minas Gerais. Por meio de análise descritiva dos dados, aplicação do teste Qui-quadrado e a utilização da Análise de Correspondência, foi possível conhecer o perfil das pessoas com deficiência nessas regiões. Em ambas as regiões, verificou-se que o domicílio urbano está associado às deficiências visual e motora para habitantes do sexo feminino. A deficiência auditiva está associada ao sexo masculino tanto em domicílio urbano e rural, e verificou-se ainda uma relação entre pessoas de baixa renda e dificuldades relacionada à visão.

Palavras-chave: Qui-quadrado; Análise de Correspondência; Perfil; Associação; Variáveis Socioeconômicas.

\begin{abstract}
Throughout history there have always been people with physical, sensory or intellectual limitation, whose career was marked by ignorance, indifference, prejudice and struggles in pursuit of social inclusion. In Brazil, the 2000 census recorded 24.5 million people with a disability. The evaluation of the disabled in a region enables better understanding of the conditions and realities in which these people are located. Few studies focused on people with disabilities, specifically in relation to the quality of life of these people in the regions of Triangulo Mineiro and Alto Parnaíba of Minas Gerais. Through descriptive analysis of the data, application of chi-square test and the use of correspondence analysis, it was possible to know the profile of disabled people in these regions. In both regions, it was found
\end{abstract}


that urban household is associated with visual impairments and motor for female population. Hearing loss is associated with males in both urban and rural household, and still found a relation between the poor and difficulties related to vision.

Keywords: Chi-square; Correspondence Analysis; Profile; Association; Socioeconomic Variables.

\section{INTRODUÇÃO}

Para a Convenção Internacional dos Direitos da Pessoa com Deficiência "as pessoas com deficiência são aquelas que têm impedimentos de longo prazo de natureza física, mental, intelectual ou sensorial, os quais, com interação com diversas barreiras, podem obstruir sua participação plena e efetiva na sociedade em igualdades de condições com as demais pessoas". O Decreto 3298/89, que regulamentou a Lei 7853/89, em seu art. $3^{\circ}$ define deficiência como "toda perda ou anormalidade de uma estrutura ou função psicológica, fisiológica ou anatômica que gere incapacidade para o desempenho de atividade, dentro do padrão considerado normal para o ser humano“.

A Organização das Nações Unidas (ONU) (Resolução no 2542) define o termo pessoa portadora de deficiência (PPD) como aquela pessoa que "Sofreu perda, ou possua anormalidade, de uma estrutura ou função psicológica, fisiológica ou anatômica que venha gerar uma incapacidade para o desempenho de atividade dentro do padrão considerado normal para o homem, podendo a gênese estar associada a uma deficiência física, auditiva, visual, mental, quer permanente, quer temporária" (Herculano, et.al, 2004).

O conceito de portador de deficiência abrange um conjunto amplo de características. As deficiências podem ser físicas, sensoriais (da visão ou da audição) ou intelectuais. Podem ter um impacto brando na capacidade de trabalho e de interação com o meio físico e social ou consequências maiores, que requerem apoio e assistência proporcionais (Fontes, 2001).

As deficiências possuem origens diversas, podendo ser pré-natal; congênitas; doenças da mãe ou do feto; pós-natal; doenças infecciosas; doenças não-infecciosas e provenientes de acidentes, como por exemplo, automobilísticos, ferimentos por arma de fogo, acidentes de trabalho. Existem também causas relacionadas a problemas sociais, tais como a falta de acesso à informação, de saneamento básico, de higiene e subnutrição (Fontes, 2001).

Cohen (1998) verificou que são vários os fatores que contribuem para o aumento do número de deficientes e sua marginalização, em países como o Brasil. Dentre estes fatores ele mencionou, a fome; a pobreza; programas inadequados de assistência social, saúde, educação, formação profissional e emprego; acidentes na indústria, na agricultura ou nos transportes; a contaminação do meio ambiente; o uso imprudente de medicamentos; a baixa prioridade concedida, no contexto do desenvolvimento 
social e econômico, às atividades relativas à equiparação de oportunidades; o crescimento demográfico; a violência urbana e outros fatores indiretos.

Segundo Silva (1986) sempre existiram ao longo da história pessoas com alguma limitação física, sensorial ou intelectual. Ao longo dos séculos e nas mais variadas sociedades a trajetória dessas pessoas foi marcada pela ignorância, indiferença, preconceito e lutas em busca da inclusão social. O preconceito, a discriminação, a negligência e a falta de conhecimento sobre as dificuldades enfrentadas por essa parcela da população são fatores que dificultam sua aceitação e participação como membros normais na sociedade.

Na Antiguidade, a deficiência inexistia enquanto problema, sendo que, com relação às crianças portadoras de deficiências físicas, a atitude adotada era a da "exposição", ou seja, o abandono ao relento (Aranha,1979; Pessotti,1984). Na Idade Média, em função da disseminação das ideias cristãs, o diferente não-produtivo (deficiente) adquire, nesta época, status humano, também possuidor de uma alma. Em sendo assim, não mais se fazia aceitável sua exterminação. Gradativamente, sua custódia e cuidado passaram a ser assumidos pela família e pela Igreja, embora não haja qualquer evidência de esforços específicos e organizados de lhes prover de acolhimento, proteção, treinamento ou tratamento (Pessotti, 1984). Caracterizado como fenômeno metafísico e espiritual, a deficiência foi atribuída ora a desígnios divinos, ora à possessão do demônio. Por uma razão ou por outra, a atitude principal da sociedade com relação ao deficiente era de intolerância e de punição, representada por ações de aprisionamento, tortura, açoites e outros castigos severos (Aranha, 1995).

No início da Revolução Burguesa, no final do século XV, começaram a ser vistos como deficientes os indivíduos não produtivos, que oneram a sociedade no que se refere ao seu sustento e manutenção. $\mathrm{O}$ avanço no caminhar da medicina favorece a leitura organicista da deficiência, a partir das quais a demência e a amência deixam de ser vistas com problemas teológico e moral e passam a ser vistas como problema médico (Pessotti, 1984). Nos séculos XVII e XVIII, multiplicam-se as leituras de deficiência enquanto fenômeno, especialmente nas áreas médica e educacional, encaminhando uma grande diversidade de atitudes: desde a institucionalização em conventos e hospícios até o ensino especial (Aranha, 1995).

Nos século XIX, o modo de produção capitalista continua a se fortalecer, mantendo o sistema de valores e de normas sociais. A atitude de responsabilidade pública pelas necessidades do deficiente começa a desenvolver-se, embora existisse ainda a tendência de se manter a instituição fora do setor público, sob a iniciativa e sustentação do setor privado (Aranha, 1995).

No século XX, as duas Guerras Mundiais impulsionaram o desenvolvimento da reabilitação científica, não só pela carência de mão-de-obra surgida no período pós-guerra, mas também pela necessidade de propiciar uma atividade remunerada e uma vida social digna aos soldados mutilados. 
Na década de 1960, a Guerra do Vietnã foi responsável por um número crescente de portadores de deficiência. Cria-se o conceito da integração (Herculano et al., 2004).

No Brasil, fatos ocorridos nas décadas de 1980 e 1990 são referências que marcam o processo de consolidação dos direitos de pessoas portadoras de deficiência. No contexto de redemocratização do país, na década de 1980, a ação organizada dessa parcela da população gerou, ao lado de outros atores sociais, importantes conquistas na esfera institucional, essencialmente no campo da legislação. Pessoas portadoras de deficiência foram discriminadas positivamente em vários pontos da Constituição promulgada em 1988, e a Lei n. 7853/89 responsabilizou o poder público a assegurar o pleno exercício de seus direitos, tais como os direitos à educação, à saúde, ao trabalho e ao lazer, entre outros (Almeida e Campos, 2002).

Essas conquistas, porém, não barraram o avanço dos processos sociais de exclusão que, em sentido oposto, aprofundaram as contradições na sociabilidade desse segmento. Se, por um lado, a legislação garantiu a participação na produção e partilha de bens, serviços e valores sociais, por outro, tal como ocorreu com outros segmentos sociais, verificou-se a ausência de políticas que oferecessem suporte ao real exercício desses direitos (Almeida e Campos, 2002).

De acordo com Aranha (2001), os projetos e ações públicas voltadas á educação, saúde, lazer, turismo, cultura quando aberto aos deficientes são em geral segregatórios, deixando para a pessoa com deficiência ou sua família a responsabilidade sobre o alcance do acesso. Entretanto, as pessoas com deficiência ainda continuam a enfrentar barreiras no que diz respeito á sua participação como membros normais na sociedade.

Um dos principais problemas que dificultam a inserção dos portadores de deficiência na sociedade em geral, principalmente no mercado de trabalho, refere-se às chamadas barreiras arquitetônicas (Pastore, 2000). As barreiras físicas, também são problemas que as pessoas com deficiência enfrentam em seu dia-a-dia. Cohen (1998) aponta inúmeras barreiras físicas existentes: calçadas estreitas, com pavimento deteriorado e com obstáculos difíceis de serem detectados por pessoas portadoras de deficiência visual; portas demasiado estreitas para que se passe uma cadeira de rodas; escadas inacessíveis em edifícios; elevadores pequenos e sem sinalização em braille; ônibus, trens e aviões inacessíveis; telefones e interruptores de luz colocados fora da área de alcance ou inexistência de banheiros adaptados. O referido autor aponta que estas barreiras são o resultado da despreocupação e do despreparo dos técnicos das diversas áreas.

Além disso, Neri e Soares (2004) acreditam que grande parte das pessoas com deficiência, em idade produtiva, não estão inseridas no mercado formal. Tal fato parece estar relacionado com a falta de acesso dessas pessoas á educação. Para Oliveira (2013) a dificuldade de acesso a educação, a infraestrutura inadequada, o preconceito e falta de informação por parte de escolas e empresas são 
fatores que fazem com que essas pessoas apresentem um menor nível de escolaridade, o que dificulta o ingresso delas no mercado formal de trabalho.

Atualmente, um movimento organizado de pessoas com deficiência tem lutado pela equiparação de oportunidades. É possível afirmar que houve um amadurecimento desse segmento ao abandonar uma perspectiva meramente assistencialista e situar o debate relacionado às pessoas com deficiência no paradigma das políticas públicas e dos direitos humanos. A diversidade entre os indivíduos é um dado biológico, sobre o qual não há contestação. Entretanto, as diferenças de oportunidades e as desigualdades sociais decorrem das relações humanas e da concentração de poder, exigindo intervenções para que se evitem injustiças (Cortella, 1996).

No Brasil, o censo de 2000 registrou 24,5 milhões de pessoas com algum tipo de deficiência, ou seja, 14,5\% da população do país. Já o censo de 2010 apontou que 45,6 milhões de pessoas $(23,9 \%)$ residentes no território brasileiro possuem alguma das deficiências pesquisadas. Além disso, verificou-se que, coincidentemente, Minas Gerais apresenta uma proporção de pessoas com deficiência muito próxima à média do país (Baptista e Rigotti, 2013).

Os estudos relacionados aos deficientes no Estado de Minas Gerais (no nível de municípios) se tratam de um tema relativamente pouco explorado e estudado no meio acadêmico (Baptista e Rigotti, 2013).

A Mesorregião do Triângulo Mineiro e Alto Paranaíba é uma região formada pela união de 66 municípios, localizada na região oeste de Minas Gerais. Segundo Júnior (2001) esta região tem sido lembrada pelo importante papel que cumpre no desenvolvimento econômico e social de Minas Gerais, Estado em que está inserida, e do País como um todo.

A avaliação dos deficientes de uma região permite conhecer melhor as condições e realidades nas quais essas pessoas estão inseridas. São poucos os estudos voltados às pessoas com deficiência, e especificamente em relação à qualidade de vida dessas pessoas nas regiões do Triângulo Mineiro e Alto Paranaíba de Minas Gerais não foi encontrado nenhum estudo. Por esse motivo faz-se necessário um diagnóstico dessa parcela da população, de modo que os resultados contribuam para o desenho e implementação de políticas públicas e ações sociais específicas para essas regiões.

Assim, o presente trabalho tem como objetivo avaliar a qualidade de vida das pessoas deficientes nas regiões do Triângulo Mineiro e Alto Paranaíba, a partir do censo demográfico de 2010 (IBGE).

\section{METODOLOGIA}

Para analisar a qualidade de vida das pessoas deficientes residentes nas regiões do Triângulo Mineiro e Alto Paranaíba do Estado de Minas Gerais é muito importante conhecer a realidade de cada 
uma das deficiências visual, auditiva, motora e mental ou intelectual, para que a população e autoridades competentes tenham consciência das dificuldades e problemas vivenciados pelos deficientes procurem subsidiar políticas e ações que favoreçam estes indivíduos.

Os dados em estudo foram obtidos pelo Instituto Brasileiro de Geografia e Estatística (IBGE) por meio do Censo Demográfico 2010, onde se pesquisou a população que declarou ter algum tipo de deficiência nas regiões do Triângulo Mineiro e Alto Paranaíba, sendo a deficiência classificada em visual, auditiva, motora e mental/intelectual, e os seus graus de severidade classificados em "Não consegue de modo algum", "Grande dificuldade" e "Alguma dificuldade". Para descrever o perfil das pessoas deficientes em relação às variáveis socioeconômicas, as análises foram feitas separadamente para cada região, e por meio de análises descritivas e representação gráfica dos dados avaliou-se para cada região os tipos de deficiência em relação a variável Domicílio, classificada em Urbano ou Rural; a variável Renda, agrupada em quatro novas classificações, sendo essas: Menos de 2 salários mínimos, De 2 a 5 salários mínimos, De 5 a 10 salários mínimos e Mais de 10 salários mínimos; e a variável Sexo, classificada em Masculino e Feminino.

O teste de independência de Qui-quadrado $\left(\chi^{2}\right)$ se fez necessário para verificar a existência de associação entre os tipos de deficiência (visual, auditiva, motora e mental/intelectual) e cada variável em estudo. Segundo Fonseca e Martins (2011), para efetuar o teste $\chi^{2}$ precisa-se seguir os procedimentos abaixo:

Enunciar as hipóteses $\mathrm{H}_{0}$ e $\mathrm{H}_{1}$.

$\mathrm{H}_{0}$ : as variáveis são independentes, ou as variáveis não estão associadas.

$\mathrm{H}_{1}$ : as variáveis são dependentes, ou as variáveis estão associadas.

Fixar o valor do nível de significância $(\alpha)$. Escolher a variável Qui-quadrado com graus de liberdade $=(1-1)(\mathrm{c}-1)$, em que $1=$ número de linhas da tabela de contingência e $\mathrm{c}=$ número de colunas.

Com o auxílio da tabela $\chi^{2}$, determinar a Região de Aceitação e Região Crítica.

Cálcular o valor da estatística do teste:

$$
\chi^{2}=\frac{\sum_{i=1}^{k}\left(f o_{i}-f e_{i}\right)^{2}}{f e_{i}}
$$

Em que $f o_{i}$ é a frequência observada e $f e_{i}$ é a frequência esperada 
Conclusão:

$\chi_{c a l}^{2}<\chi_{t a b}^{2}$, não se pode rejeitar $H_{0}$, as variáveis são independentes.

$\chi_{c a l}^{2}>\chi_{t a b}^{2}$, rejeita-se $H_{0}$, concluindo-se ao nível de significância $\alpha$, que as variáveis são dependentes ou estão associadas.

A análise de correspondência é uma técnica multivariada utilizada para o exame de relações geométricas do cruzamento, ou contingenciamento, de variáveis categorizadas (variáveis qualitativas). Permite analisar a relação entre as duas variáveis graficamente em um espaço multidimensional, de modo que se possa verificar que categorias de uma variável são similares às outras ou quais categorias das duas variáveis são relacionadas (Oliveira, 2013). Por meio dessa técnica, foi possível verificar a associação existente entre os diferentes tipos de deficiência e as características socioeconômicas.

\section{RESULTADOS E DISCUSSÃO}

Na Tabela 1 são apresentadas as frequências percentuais das pessoas com algum tipo de deficiência nas regiões do Triângulo Mineiro e Alto Paranaíba. De modo geral, pode-se observar que a porcentagem de pessoas que possuem deficiência visual é alta comparada com as demais deficiências. Ao confrontar os resultados das regiões do Triângulo Mineiro e Alto Paranaíba, verificou-se que são bem semelhantes.

Tabela 1: Frequências percentuais das pessoas com algum tipo de deficiência nas regiões do Triângulo Mineiro e Alto Paranaíba.

\begin{tabular}{ccccc}
\hline Região & Visual & Auditiva & Motora & Mental/Intelectual \\
\hline Alto Paranaíba & $57 \%$ & $16 \%$ & $22 \%$ & $5 \%$ \\
Triângulo Mineiro & $56 \%$ & $17 \%$ & $22 \%$ & $5 \%$ \\
\hline
\end{tabular}

Na Figura 1 são apresentadas as porcentagens referentes ao número de habitantes do Triângulo Mineiro com algum tipo de deficiência de acordo com o sexo e tipo de domicílio em que reside. Notase que o número de habitantes que possuem deficiência visual é maior tanto na população que reside na área urbana quanto na que reside na área rural, e que a porcentagem de pessoas com deficiência visual do sexo feminino é maior que a do sexo masculino, em ambos os tipos de domicílio.

No caso dos habitantes do sexo masculino as porcentagens de pessoas com deficiência motora e auditiva são semelhantes no domicílio urbano e rural. O mesmo acontece com os habitantes do sexo feminino, porém percebe-se um maior número de casos de deficiência motora comparada a deficiência 
auditiva. A deficiência com menor porcentagem de casos é a mental/intelectual, tanto em habitantes do sexo feminino quanto em habitantes do sexo masculino, em ambos os tipos de domicílio.

Figura 1: Gráfico da porcentagem de pessoas com alguma deficiência na região do Triângulo Mineiro por tipo de domicílio e sexo.

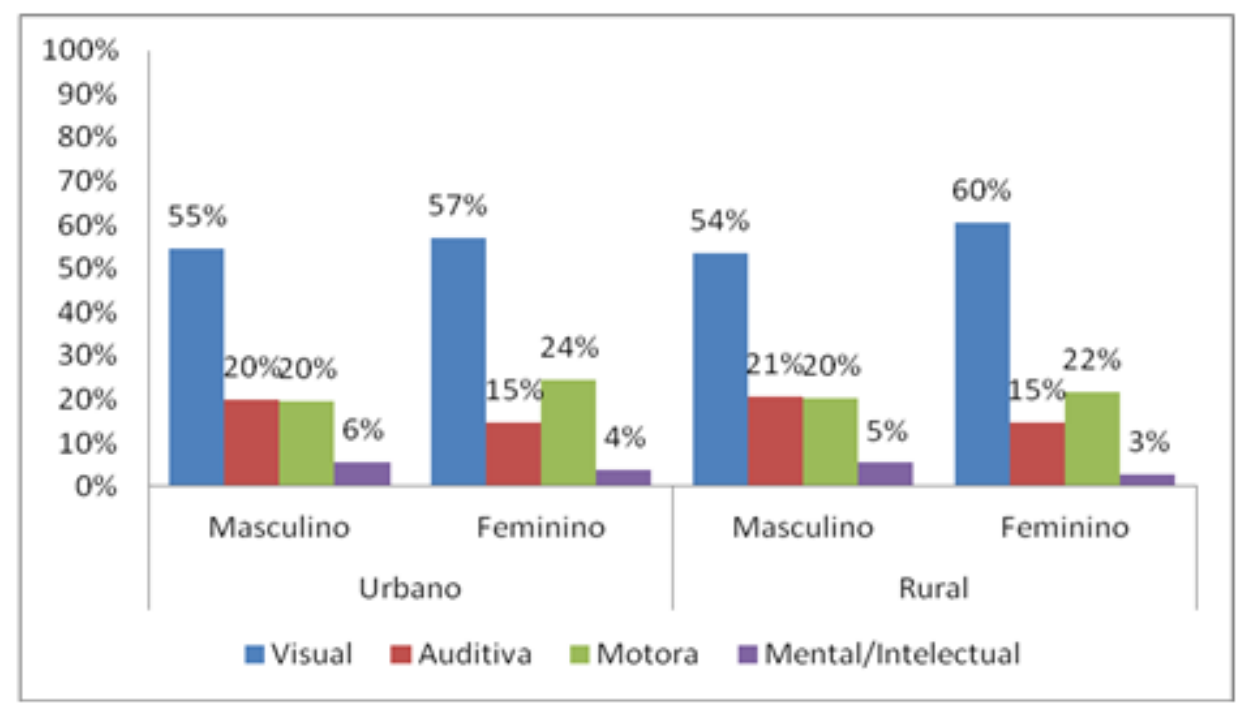

Em relação às porcentagens relacionadas às pessoas com deficiências na região do Alto Paranaíba de acordo com o sexo e tipo de domicílio, nota-se que os resultados são similares aos obtidos para a região do Triângulo Mineiro. Estes resultados são ilustrados na Figura 2.

Figura 2: Gráfico da porcentagem de pessoas com alguma deficiência na região do Alto Paranaíba por tipo de domicílio e sexo.

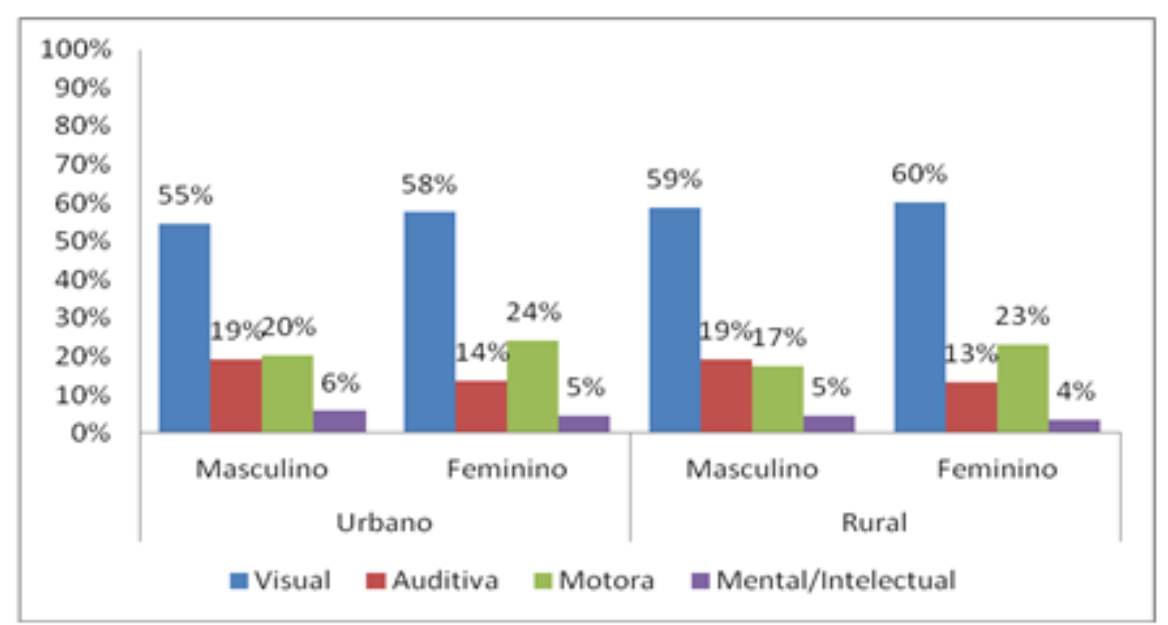

De acordo com a Tabela 2, percebe-se que a porcentagem de habitantes da região do Triângulo Mineiro que possuem algum tipo de deficiência é um pouco maior em pessoas com renda entre 2 e 10 
salários mínimos, enquanto na região do Alto Paranaíba essa porcentagem é maior para pessoas que possuem mais de 10 salários mínimos.

Tabela 2: Porcentagem de habitantes da região do Triângulo Mineiro e Alto Paranaíba de acordo com a presença e ausência de deficiência por renda.

\begin{tabular}{ccccc}
\hline \multirow{2}{*}{ Renda } & \multicolumn{2}{c}{ Triângulo Mineiro } & \multicolumn{2}{c}{ Alto Paranaíba } \\
\cline { 2 - 4 } & \multicolumn{3}{c}{ Deficiência } \\
\cline { 2 - 4 } & Presença & Ausência & Presença & Ausência \\
\hline Menos de 2 salários mínimos & $24 \%$ & $76 \%$ & $24 \%$ & $76 \%$ \\
De 2 a 5 salários mínimos & $19 \%$ & $81 \%$ & $18 \%$ & $82 \%$ \\
De 5 a 10 salários mínimos & $19 \%$ & $81 \%$ & $18 \%$ & $82 \%$ \\
Mais de 10 salários mínimos & $18 \%$ & $82 \%$ & $24 \%$ & $76 \%$ \\
\hline
\end{tabular}

$\mathrm{Na}$ Figura 3 tem-se a porcentagem referente aos habitantes que possuem algum tipo de deficiência da região do Triângulo Mineiro de acordo com sua respectiva renda. A porcentagem de pessoas que possuem deficiência visual é alta independente de sua renda. Em relação à porcentagem de pessoas com deficiência auditiva, motora e mental/intelectual, as porcentagens são bastante semelhantes em todas as categorias. Resultados da porcentagem referente aos habitantes da região do Alto Paranaíba que possuem algum tipo de deficiência em relação à renda foram semelhantes aos apresentados para a região do Triângulo Mineiro, portanto, não foram apresentados.

Figura 3: Gráfico da porcentagem de pessoas com alguma deficiência na região do Triângulo Mineiro por renda.

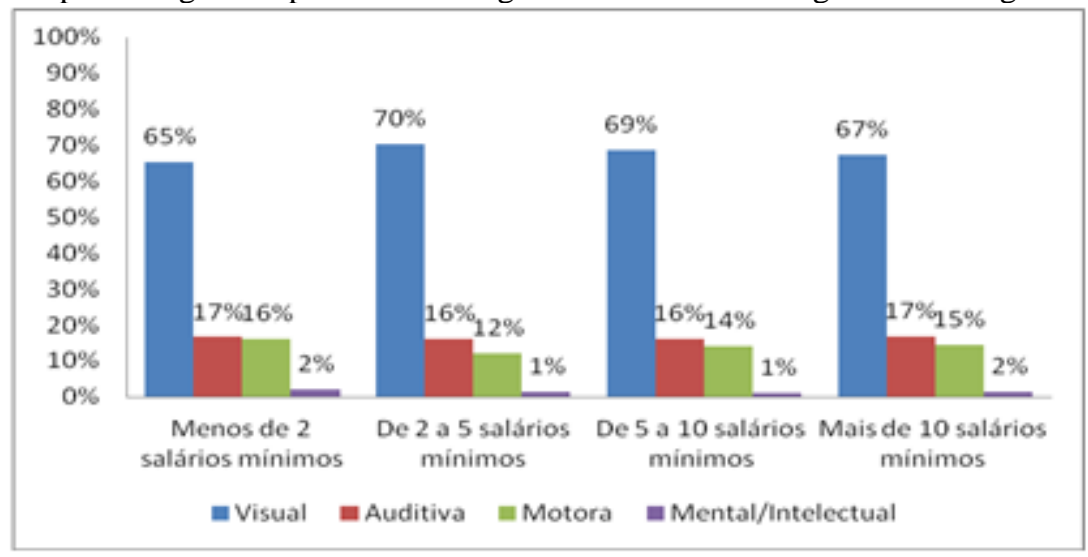

O teste de independência de Qui-quadrado $\left(\chi^{2}\right)$ é um teste de hipóteses que se destina a encontrar um valor da dispersão para duas variáveis nominais, avaliando a associação existente entre variáveis qualitativas. Logo, este teste foi utilizado para verificar a existência de associação entre os tipos de deficiência (visual, auditiva, motora e mental/intelectual) e as variáveis socioeconômicas. Resultados com um p-valor abaixo do nível de significância adotado tem-se a rejeição da hipótese nula, ou seja, 
conclui-se que existe associação entre os grupos, ou seja, que as variáveis são dependentes. Adotando um nível de confiança de 5\%, conclui-se que os tipos de deficiência e todas as variáveis socioeconômicas em estudo estão associados, tanto para região do Triângulo Mineiro quanto para a região do Alto Paranaíba, conforme são apresentados os resultados na Tabela 3.

Tabela 3: Valores do Qui-quadrado e p-valor das associações entre tipos de deficiência e variáveis socioeconômicas com um nível de confiança de $95 \%$.

\begin{tabular}{ccccc}
\hline \multirow{2}{*}{ Variáveis } & \multicolumn{2}{c}{ Triângulo Mineiro } & \multicolumn{2}{c}{ Alto Paranaíba } \\
\cline { 2 - 5 } & $\chi^{2}$ & p-valor & $\chi^{2}$ & p-valor \\
\hline Deficiência/Domicílio & 59.9446 & $6.041 \mathrm{e}-13$ & 94.0042 & $<2.2 \mathrm{e}-16$ \\
Deficiência/Renda & 598.7055 & $<2.2 \mathrm{e}-16$ & 237.3118 & $<2.2 \mathrm{e}-16$ \\
Deficiência/Sexo & 4287.662 & $<2.2 \mathrm{e}-16$ & 1008.27 & $<2.2 \mathrm{e}-16$ \\
\hline
\end{tabular}

A Análise de Correspondência permite analisar a relação entre as variáveis graficamente em um espaço multidimensional, de modo que se possa verificar quais categorias de uma variável são similares ou estão associadas às categorias de outras variáveis. A Figura 4 esboça a análise de correspondência aplicada aos 37 municípios que compõem a região do Triângulo Mineiro e os graus de severidade dos tipos de deficiências. Na figura, os números 1, 2 e 3 representam os graus de severidade das deficiências, classificadas em "Não consegue de modo algum", "Grande dificuldade" e "Alguma dificuldade". As letras V, A e M representam, respectivamente, as deficiências Visual, Auditiva e Motora. A sigla MI se refere à deficiência do tipo Mental/Intelectual.

Tem-se que os municípios mais relacionados à deficiência visual no grau "Não consegue de modo algum" são Indianópolis, Ipiaçu e Araporã. Em relação a esse tipo de deficiência, no grau "Grande dificuldade" os municípios Santa Vitória e Centralina possuem maior associação, e no grau de severidade "Alguma dificuldade”, os municípios mais relacionados são Monte Alegre de Minas, Pirajuba, Uberlândia, Frutal e Patrocínio.

Em relação à deficiência auditiva e seus graus de severidade, tem-se que os municípios Uberaba e Conquista estão relacionados tanto ao grau "Não consegue de modo algum" quanto ao grau "Alguma dificuldade", e Veríssimo possui maior associação com “Não consegue de modo algum”. Já Gurinhatã e Ituiutaba são os municípios mais relacionados ao grau intermediário "Grande dificuldade".

A deficiência do tipo motora possui o município de Cascalho Rico mais associado ao grau "Não consegue de modo algum", Ituiutaba relacionado a "Grande dificuldade" e Patos de Minas e Araguari relacionados ao grau "Alguma dificuldade". Quando se trata da deficiência Mental/Intelectual, os municípios Uberaba e Conquista estão fortemente associados. 
Figura 4: Análise de Correspondência entre os municípios da região do Triângulo Mineiro e os graus de severidade dos tipos de deficiência.

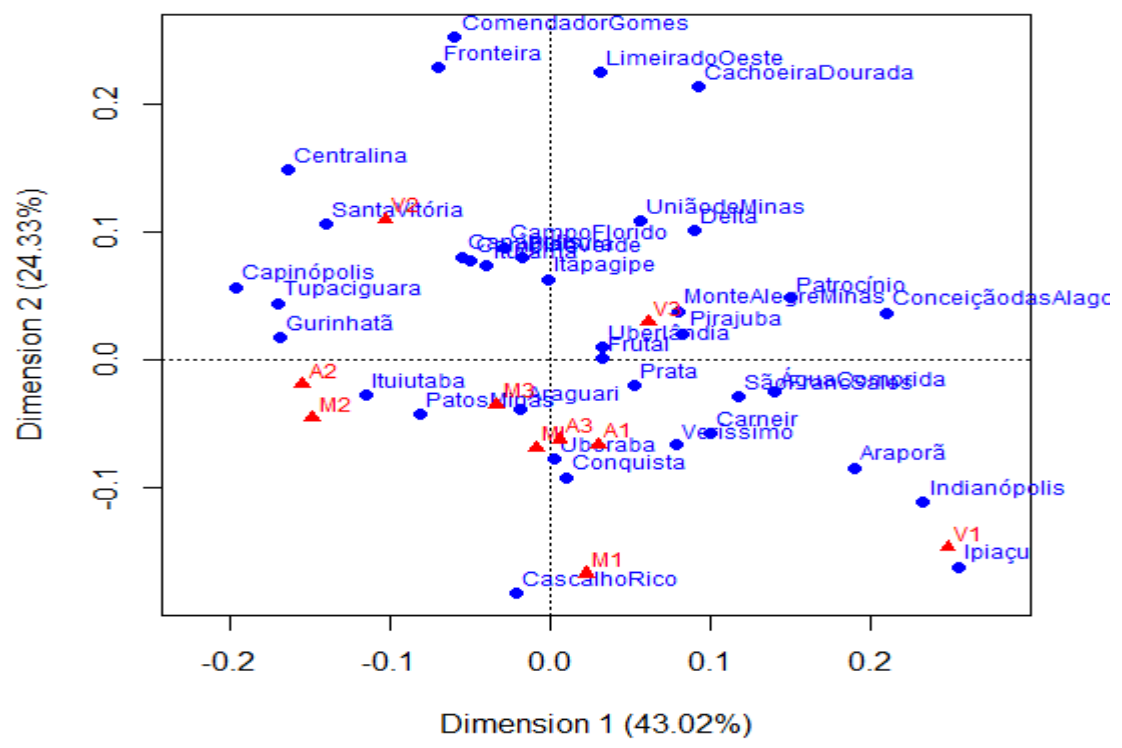

A Figura 5 mostra os resultados obtidos em relação aos 29 municípios da região do Alto Paranaíba. Tem-se que se os municípios Araxá, Arapuá e Tiros são os mais associados a deficiência visual no grau "Não consegue de modo algum", enquanto que Estrela do Sul e Perdizes são os municípios mais relacionados ao grau "Grande dificuldade" e Serrado do Salitre, Cruzeiro da Fortaleza e Monte Carmelo são os de maior relação a "Alguma dificuldade".

Em relação a deficiência auditiva nessa região, Douradoquara, Nova Ponte, Romaria e Tiros associam-se ao grau "Não consegue de modo algum”. Sacramento é o município que mais se relaciona a "Grande dificuldade", e nenhum município possui forte relação com o grau "Alguma dificuldade".

Já quando se trata da deficiência motora, Grupiara é o município mais associado ao grau "Não consegue de modo algum", e em relação aos graus "Grande dificuldade" e "Alguma dificuldade", nenhum município possui forte associação. O município de Rio Paranaíba é o mais associado à deficiência Mental/Intelectual. 
Figura 5: Análise de Correspondência entre os municípios da região do Alto Paranaíba e os graus de severidade dos tipos de deficiência.

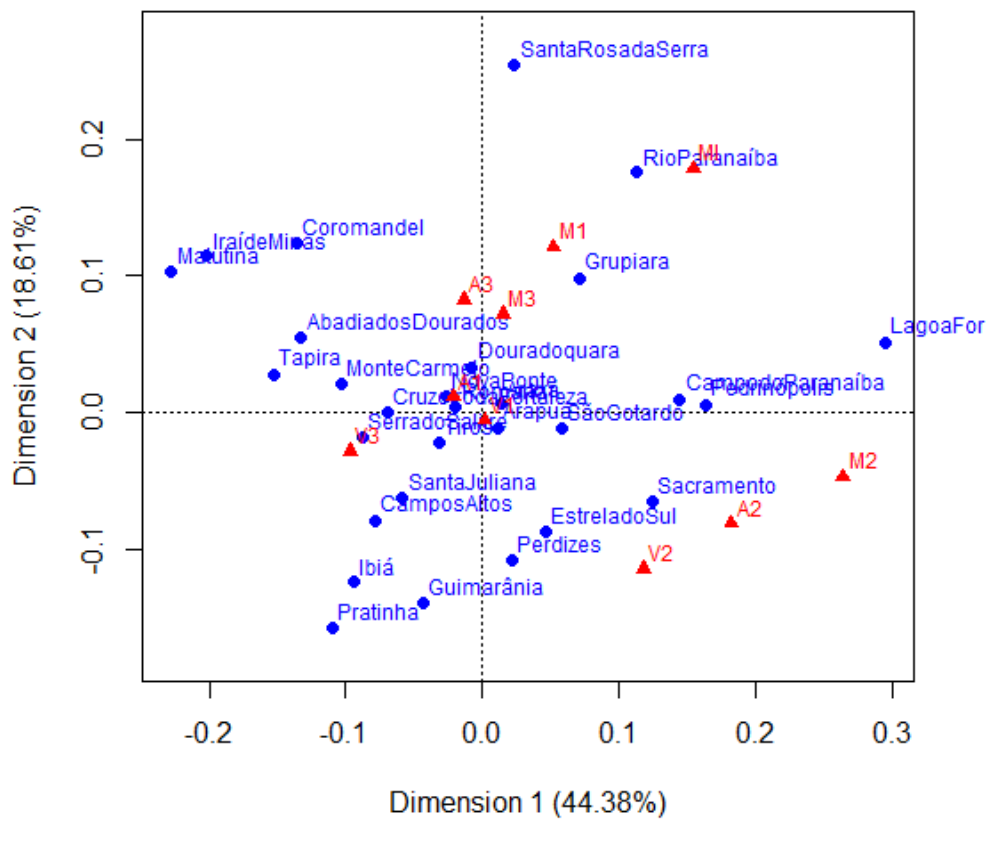

A Análise de Correspondência foi utilizada também para verificar a relação existente entre os níveis de deficiência e os níveis das variáveis socioeconômicas em estudo para cada região. A notação utilizada para os tipos de deficiência permanece a mesma, sendo que as variáveis UM e UF representam, respectivamente, a população masculina e feminina residente na área urbana, enquanto que RM e RF representam, respectivamente, a população masculina e feminina residente na área rural. As variáveis R1, R2, R3 e R4 representam as categorias relacionadas à renda, sendo, R1 os habitantes que possuem renda "Inferior a 2 salários mínimos", R2 os que possuem renda "De 2 a 5 salários mínimos", R3 os que possuem renda "De 5 a 10 salários mínimos" e R4 os que possuem renda "Maior do que 10 salários mínimos".

Na região do Triângulo Mineiro, tem-se uma associação entre os habitantes residentes na área urbana do sexo feminino e o grau "Grande dificuldade" da deficiência visual e "Alguma dificuldade" da deficiência motora (Figura 6). Com os habitantes também residentes na área urbana, porém do sexo masculino existe uma associação entre o grau "Grande dificuldade" da deficiência auditiva. Já em relação aos habitantes do sexo masculino residentes na área rural, existe uma associação com o grau "Não consegue de modo algum" da deficiência visual e "Alguma dificuldade" referente à deficiência auditiva. Percebe-se que habitantes com renda menor que 2 salários mínimos estão relacionados a deficiência visual com “Alguma dificuldade”. 
Figura 6: Análise de Correspondência entre as variáveis socioeconômicas e os graus de severidade dos tipos de deficiência da região do Triângulo Mineiro.

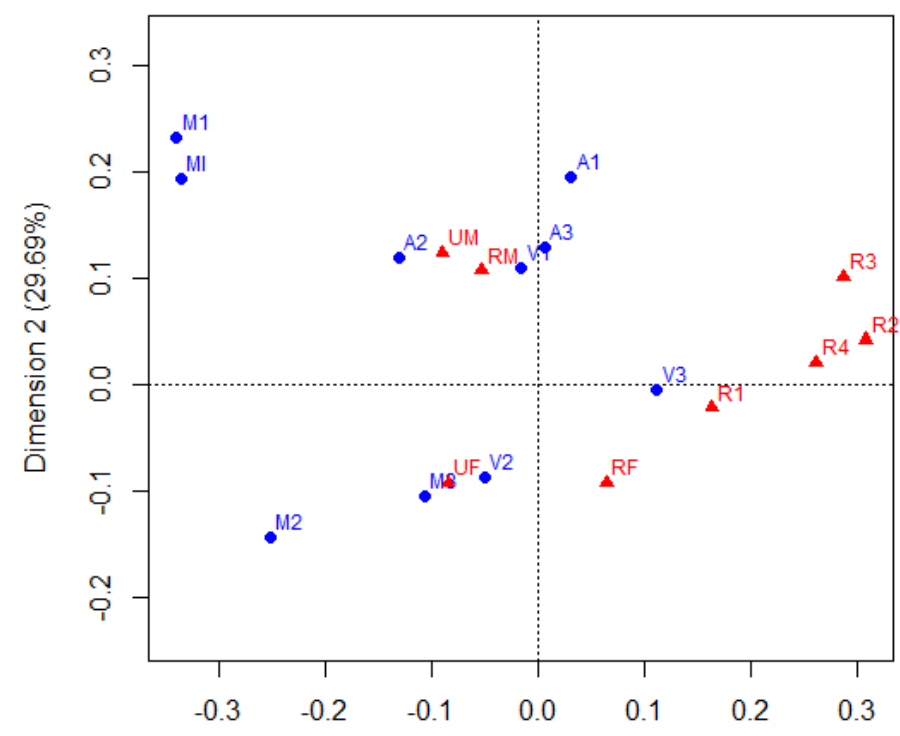

Dimension $1(62.22 \%)$

Já na região do Alto Paranaíba, pode se observar na Figura 7, uma associação entre aos habitantes do sexo feminino residentes na área urbana com a deficiência visual com o grau de "Grande dificuldade" e com a deficiência motora no grau "Alguma dificuldade". Em relação aos habitantes do sexo masculino residentes na área urbana, tem-se uma associação ao grau "Não consegue de modo algum" da deficiência do tipo auditiva. Percebe-se também uma forte relação entre os habitantes do sexo masculino residentes na área rural ao grau "Alguma dificuldade" da deficiência auditiva e uma associação entre os habitantes com renda menor que 2 salários mínimos e o grau "Alguma dificuldade” da deficiência visual.

Figura 7: Análise de Correspondência entre as variáveis socioeconômicas e os graus de severidade dos tipos de deficiência da região do Alto Paranaíba.

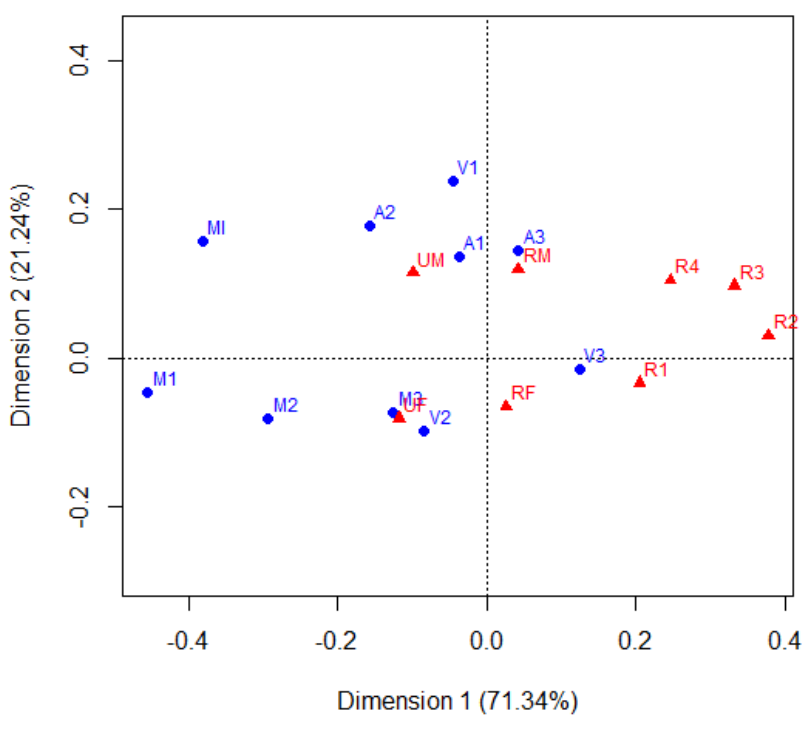




\section{CONSIDERAÇÕES FINAIS}

Tem-se por meio da análise descritiva que dentre os habitantes que residem a região do Triângulo Mineiro e Alto Paranaíba, que o tipo de deficiência mais frequente é a visual. Ambas as regiões não apresentaram diferença significativa entre si em relação ao tipo de deficiência e as variáveis domicílio, sexo e renda, sendo a deficiência visual a de maior índice em relação a todas essas variáveis.

No geral, o índice de pessoas que declaram ter algum tipo de deficiência no Triângulo Mineiro foi maior em habitantes com renda abaixo de dois salários mínimos. Já na região do Alto Paranaíba, este índice foi maior para pessoas com renda abaixo de dois salários mínimos e renda acima de 10 salários mínimos.

Através do teste Qui-quadrado conclui-se que os tipos de deficiência e as variáveis socioeconômicas em estudo possuem entre si uma associação significativa. A Análise de Correspondência se mostrou bastante eficaz para se observar os municípios de cada região que possuem maior associação com cada tipo de deficiência, além de fornecer a relação entre as variáveis socioeconômicas e os tipos de deficiência.

Em ambas as regiões tem-se que as deficiências visual e motora estão presentes em habitantes do sexo feminino residentes em ambiente urbano, sendo a deficiência visual em um maior grau de severidade que a motora. Ainda em relação aos habitantes residentes em ambiente urbano, porém do sexo masculino, constatou-se a deficiência auditiva como mais presente, sendo maior o grau de severidade na região do Alto Paranaíba. Já os habitantes do sexo masculino residentes na área rural possuem alguma dificuldade em relação à audição, mas, além disso, no Triângulo Mineiro apresentouse ainda alto grau de severidade associado à deficiência visual nesse grupo. E por fim, tem-se que em ambas as regiões, habitantes com renda inferior a dois salários mínimos possuem alguma dificuldade relacionada à visão.

Deste modo foi possível conhecer o perfil das pessoas portadoras de algum tipo de deficiência nas regiões do Triângulo Mineiro e Alto Paranaíba, a fim de que os resultados possam possibilitar ou contribuir para o desenho e implementação de políticas públicas e ações sociais específicas para essas regiões, com o objetivo de melhor a qualidade de vida dessas pessoas. 


\section{REFERÊNCIAS BIBLIOGRÁFICAS}

ALMEIDA, M. C. de.; CAMPOS, G. W. S. Políticas e modelos assistenciais em saúde e reabilitação de pessoas com deficiência no Brasil: análise de proposições desenvolvidas nas últimas duas décadas. Rev. Ter. Ocup. Univ. São Paulo, v. 13, n. 3, p. 118-26, set./dez. 2002.

ARANHA, M. S. F. (1979) Overview of the Rehabilitation Movement in the United States and Proposals for an Extende Model in Brazil. Carbondale, Illinois, USA.: Rehabilitation Institute, Southern Illinois University.

ARANHA, M. S. F. Integração social do deficiente: análise conceitual e metodológica. Universidade Estadual Paulista - Bauru. Temas em Psicologia (1995), v. 3, n. 2., p. 63-70.

ARANHA, M. S. E. Paradigmas da relação da sociedade com as pessoas com deficiência. Revista do Ministério Público do Trabalho, Ano XI, n. 21, mar. 2001. p. 160-173. Disponível em: <http://www.adion.com.br/mznews/data/paradigmas.pdf.> Acesso em: 31mar.2013.

BAPTISTA, E. A.;RIGOTTI, R. I. J. A população de deficientes no Estado de Minas Gerais: uma análise exploratória a partir dos censos demográficos de 2000 e 2010. Belo Horizonte: UFMG/CEDEPLAR, 2013. 25 p. : il. - (Texto para discussão, 487)

COHEN, R. Estratégias para promoção dos direitos das pessoas com deficiência. Seminário Direitos Humanos no século XXI. Rio de Janeiro: 1998.

CORTELLA, M.S. O espaço da ética na relação indivíduo e sociedade. In: BONETTI, Dilséa A. et al. (orgs). Serviço Social e Ética: convite a uma nova práxis. São Paulo: Cortez/CFESS, 1996.

FONTES, R. Sua empresa contratando pessoas portadoras de deficiência: aperfeiçoando sua imagem interna e externa com responsabilidade social. São Paulo: Núcleo de Desenvolvimento Profissional, Câmara Brasil Alemanha, 2002. 63p

FONSECA, J. MARTINS, G. M. Curso de Estatística. São Paulo: Atlas, 2011.

JÚNIOR, B. L. Triângulo Mineiro/Alto Paranaíba e a Microrregião de Uberlândia:

Trocas Migratórias nos Quinquênios 1975/80 e 1986/91. X Seminário sobre a Economia Mineira. Abril, 2001.

HERCULANO, C. T.; SILVA, C. H. M. da; ALMEIDA, P. de C. Inclusão de pessoas portadoras de deficiência no mercado de trabalho como exercício de responsabilidade social. Jovens Pesquisadores - 2004, 1 (1): 149-163.

NERI, M. C.; SOARES, W. L. Idade, incapacidade e o número de pessoas com deficiência. Revista Brasileira de Estudos da População, v. 21, n. 2, p. 303-321, jul./dez. 2004.

OliveirA, L. M. B. Cartilha do Censo 2010: Pessoas com deficiência. Brasilia-DF, 2012. Disponível em: <http://www.pessoacomdeficiencia.gov.br/>. Acesso em:

10/05/2013.

OLIVEIRA, O. J. de Análise de Correspondência. Universidade Federal do Pará. Belém-PA (2013). 
PASTORE, J. Oportunidades de trabalho para portadores de deficiência. 1. ed. São Paulo: LTR, 2000.

PESSOTTI, I. (1984) Deficiência Mental: da Superstição à Ciência. São Paulo: EDUSP.

SILVA, O. M. A. Epopéia Ignorada: A Pessoa deficiente na História do mundo de ontem e de hoje. São Paulo: Cedas, 1986. 